\title{
Investigating fundamentals of knowledge based economy using grounded theory
}

\author{
Asadollah Kordnaeij ${ }^{a^{*}}$, Mohsen Ebrahimi ${ }^{\mathrm{b}}$, Lotfollah Forozandeh Dehkordi ${ }^{\mathrm{a}}$ and Ali Asghar Fani ${ }^{\mathrm{a}}$
}

${ }^{a}$ Associate Professor, Department of Management, Tarbiat Modarres University, Tehran, Iran

${ }^{b}$ Phd student, Department of Management, Tarbiat Modarres University, Tehran, Iran

\section{CHRON I CLE AB S TRACT}

Article history:

Received June 4, 2014

Accepted 10 October 2014

Available online

October 142014

Knowledge based economy

Grounded theory

Knowledge

\begin{abstract}
During the past few years, knowledge has played essential role for development of economy. As a result, a new concept of knowledge based economy has been developed. Knowledge based economy is responsible for creating wealth through exploring knowledge. In new millennium, knowledge has made significant impact on socio-economic changes. The proposed study of this paper performs an empirical investigation to determine fundamentals of knowledge based economy in Iran using grounded theory. The study determines five categories including development of innovation and entrepreneurship culture, knowledge creation and distribution, creating competition in economic environment and information and communication economy.
\end{abstract}

\section{Introduction}

Knowledge is considered as the primary factor of competitive advantage in the current economic crisis and uncertain environment (Heng et al., 2012). Knowledge based economy is the basis for development of economy and there are many studies on factors influencing it (Yigitcanlar, 2014). In addition, there are also different indicators to measure knowledge advances, but the advantage for stakeholders and policy makers are limited because of insufficient classification models. Paz-Marín et al. (2015) introduced a technique to classify 54 countries (in 2007-2009) based on their progress toward a knowledge economy (KE). They first attempted to determine clusters of countries at a similar stage of development toward KE to see whether they were meaningful or not. Next, they built different techniques to determine the advancement of countries toward KE from one year to another because of its classification. Then, they compared three ordinal classifiers from the machine-learning field to select the classifier that executes the best ordinal description of the clusters. Fachinelli et al. (2014) pursued the advancement in the study of the use of the generic capital system as a value-based tool by determining the complete capital system of a Brazilian city. The study indicated that identity capital could be considered as an inducing factor for development especially in social contexts strongly anchored in local culture. According to Veselá and Klimová (2014), Slovakia is not rich in 
mineral resources, and along with other European countries, the country suffers from the financial and economic crisis. One way to escape from the crisis is to stimulate economic growth, for instance by supporting the so-called creative economy, which incorporates all areas of human activity based on original creativity and the value resulting from it. Creative industry, forming the core of the creative economy, includes industries which have their origin in individual creativity, skills and talent and which have the potential for creating wealth and employment opportunities. They tried to support the creative industries through education reform. Creative industry in mutual synergy with a knowledge-based economy may generate conditions for a strong and sustainable creative economy. It is necessary to eliminate obstacles in science and research, to ensure appropriate protection of intellectual property and to lead towards creativity.

\section{The proposed study}

The proposed study of this paper performs an empirical investigation to determine fundamentals of knowledge based economy in Iran using grounded theory. Fig.1 demonstrates the proposed study of this paper.



Fig. 1. The proposed study of ground theory (Vasconcelos, 2007)

Grounded Theory Method (GT) is considered as a systematic methodology in the social sciences, which involves the discovery of theory through the analysis of some data. GT is a research technique, which operates almost in a reverse fashion from traditional social science studies. Rather than initiating with a hypothesis, the primary step of GT is concentrated on data collection, through a variety of techniques. From the data gathered, the primary points are considered with a series of codes, which are extracted from the whole text. The codes are then categorized into similar concepts to make the data more workable. In terms of these concepts, groups are formed, which are the basis for the creation of a theory, or a reverse engineered hypothesis. This may be conflict with the traditional ones, where one chooses a theoretical framework, and only then uses this model to the phenomenon to be studied. Table 1 shows details of GT technique.

\section{Table 1}

The summary of GT steps

\begin{tabular}{|c|c|}
\hline Stage & Purpose \\
\hline Codes & Identifying anchors that allow the key points of the data to be gathered \\
\hline Concepts & Collections of codes of similar content that allows the data to be grouped \\
\hline Categories & Broad groups of similar concepts that are used to generate a theory \\
\hline Theory & A collection of categories that detail the subject of the research \\
\hline
\end{tabular}


GT method is a systematic generation of theory from data, which includes inductive and deductive thinking. The primary objective is to formulate different hypotheses based on conceptual ideas such that we could attempt to examine them generated by comparing conceptualized data on various levels of abstraction, and these comparisons may include deductive steps. The other objective of GT study is to discover the participants' main concern and how they continually attempt to resolve the issue. GT does not aim for the "truth" but to conceptualize the circumstances by applying empirical research. GT looks like what many researchers do when retrospectively formulating new hypotheses to fit data. Nevertheless, when applying the grounded theory method, we may not formulate the hypotheses in advance since preconceived hypotheses result in a theory ungrounded from the data (Glaser \& Strauss, 1967).

When comparing different incidents in a certain area, the emerging concepts and their relationships are in reality probability statements. Therefore, GT is a general technique, which could apply any sort of data in forms of qualitative or quantitative (Glaser, 2001, 2003). Nevertheless, although working with probabilities, most GT investigations are considered as qualitative since statistical methods are not used. The results of GT are not based on any sort of statistically significant probabilities but a set of probability statements about the relationship between concepts, or an integrated set of conceptual hypotheses using some empirical data (Glaser 1998). Validity in its traditional sense is not an important issue in GT (Glaser \& Strauss 1967, Glaser 1978, Glaser 1998).

The proposed study of this paper performed all GT steps mentioned in Table 1 and after coding the data, we have extracted the five categories including development of innovation and entrepreneurship culture, knowledge creation and distribution, creating competition in economic environment and information and communication economy. Table 1 demonstrates the results of our investigation.

\section{Table 1}

The summary of the implementation of GT technique on components influencing on KM economy

\begin{tabular}{|c|c|}
\hline Dimension & Components \\
\hline \multirow{5}{*}{$\begin{array}{l}\text { Development of innovation } \\
\text { and entrepreneurship culture }\end{array}$} & Providing support for intellectual property owners and innovators \\
\hline & Creating dialog for innovation and entrepreneurship in society \\
\hline & Encouraging entrepreneurs in society \\
\hline & Building market for ideas \\
\hline & Building desirable culture to support entrepreneurs \\
\hline \multirow{6}{*}{$\begin{array}{l}\text { Knowledge creation } \\
\text { and distribution }\end{array}$} & Science and technology park development \\
\hline & Building appropriate strategies for helping top graduates \\
\hline & Building science and technology parks associated with universities \\
\hline & Help in commercializing innovative ideas \\
\hline & Help in commercializing research ideas \\
\hline & Research and development programs for organizations \\
\hline \multirow{6}{*}{$\begin{array}{l}\text { Creating competition } \\
\text { in economic environment }\end{array}$} & The role of media in building competitive market \\
\hline & Building a legal system to support innovators \\
\hline & Creating motivation among people to support innovators \\
\hline & Developing new markets for innovative ideas \\
\hline & Development of private sector \\
\hline & Building a strong relationship between universities and industries \\
\hline \multirow{6}{*}{$\begin{array}{l}\text { Creative human resources } \\
\text { and continuous training }\end{array}$} & Human resources development through investment in knowledge \\
\hline & Meritocracy in hiring system as well as promotion plans \\
\hline & Providing education in the area of information technology \\
\hline & Promotion plans \\
\hline & In-service training \\
\hline & Helping society learn about information technology in early stage \\
\hline \multirow{6}{*}{$\begin{array}{l}\text { Economy based on } \\
\text { information and technology }\end{array}$} & Building some facilities to register firms through website \\
\hline & Development of internet in society \\
\hline & Electronic government and e-business development \\
\hline & Development of information and communication infrastructures \\
\hline & Innovation in firms' competitive advantages \\
\hline & Support on online services \\
\hline
\end{tabular}




\section{Discussion and conclusion}

As we can observe from the results of Table 1, there are five suggestions for the development of innovation and entrepreneurship culture including providing support for intellectual property owners and innovators, creating dialog for innovation and entrepreneurship in society, encouraging entrepreneurs in society, building market for ideas and building desirable culture to support entrepreneurs. In terms of knowledge creation and innovation, science and technology park development is considered as an important factor for development of knowledge based economy followed by building appropriate strategies for helping top graduates, building science and technology parks associated with universities. In addition, there must be a good support in commercializing innovative ideas as well as commercializing research ideas and finally, research and development programs for organizations are the most important factors for development of new economy. Creating competition in economic environment is the third important factor in our study. The people who were surveyed in this investigation believed that the role of media in building competitive market must be improved. We also need to build a legal system to support innovators, creating good motivation among people to support innovators. In addition, the surveyed people believed that developing new markets for innovative ideas plays essential role on helping knowledge based economy. Moreover, development of private sector and building a strong relationship between universities and industries are among other issues, which must be considered in this study. Creative human resources and continuous training is another important factor for development of knowledge based economy and finally, the study has indicated that information technology was the most important component of knowledge based economy and we need to facilities all actions needed through information technology infrastructures.

\section{References}

Fachinelli, A. C., Carrillo, F. J., \& D’Arisbo, A. (2014). Capital system, creative economy and knowledge city transformation: Insights from Bento Gonçalves, Brazil. Expert Systems with Applications, 41(12), 5614-5624.

Glaser, B., \& Strauss, A. (1967). The discovery of grounded theory. 1967. Weidenfield \& Nicolson, London.

Glaser, B. G. (1978). Theoretical sensitivity: Advances in the methodology of grounded theory (Vol. 2). Mill Valley, CA: Sociology Press.

Glaser, B. (1992). Basics of grounded theory analysis. Mill Valley, CA: Sociology Press.

Glaser, B. G. (1998). Doing grounded theory: Issues and discussions. Sociology Press.

Glaser, B. G. (2001). The grounded theory perspective: Conceptualization contrasted with description. Sociology Press.

Glaser, B. G. (2003). The grounded theory perspective II: description s remodeling of grounded theory methodology. Sociology Press.

Heng, L. H., Othman, N. F. M., Rasli, A. M., \& Iqbal, M. J. (2012). Fourth pillar in the transformation of production economy to knowledge economy. Procedia-Social and Behavioral Sciences, 40, 530-536.

Paz-Marín, M. D. L., Gutiérrez-Peña, P. A., \& Hervás-Martínez, C. (2015). Classification of countries' progress toward a Knowledge Economy based on machine learning classification techniques. Expert Systems with Applications, 42(1), 562-572.

Vasconcelos, A. C. (2007). The use of grounded theory and of arenas/social worlds theory in discourse studies: a case study on the discursive adaptation of information systems. Electronic Journal of Business Research Methods, 5(2), 125-136.

Veselá, D., \& Klimová, K. (2014). Knowledge-based economy vs. creative economy. ProcediaSocial and Behavioral Sciences, 141, 413-417.

Yigitcanlar, T. (2014). Position paper: Benchmarking the performance of global and emerging knowledge cities. Expert Systems with Applications, 41(12), 5549-5559. 